\title{
Abruzzo-Erickson syndrome
}

INSERM

\section{Source}

INSERM. (1999). Orphanet: an online rare disease and orphan drug data base. Abruzzo-

Erickson syndrome. ORPHA:921

An orofacial clefting syndrome that is characterized by a cleft palate, ocular coloboma,

hypospadias, mixed conductive-sensorineural hearing loss, short stature, and radio-ulnar synostosis. 